\title{
Extracorporeal Membranous Oxygenation Mimics Aortic Dissection on CAT Scan.
}

\author{
Philip Batista \\ Thomas Jefferson University \\ Nicholas C. Cavarocchi \\ Jefferson Medical College \\ Hitoshi Hirose \\ Thomas Jefferson University
}

Follow this and additional works at: https://jdc.jefferson.edu/surgeryfp

Part of the Surgery Commons

Let us know how access to this document benefits you

\section{Recommended Citation}

Batista, Philip; Cavarocchi, Nicholas C.; and Hirose, Hitoshi, "Extracorporeal Membranous Oxygenation Mimics Aortic Dissection on CAT Scan." (2013). Department of Surgery Faculty Papers. Paper 80.

https://jdc.jefferson.edu/surgeryfp/80

This Article is brought to you for free and open access by the Jefferson Digital Commons. The Jefferson Digital Commons is a service of Thomas Jefferson University's Center for Teaching and Learning (CTL). The Commons is a showcase for Jefferson books and journals, peer-reviewed scholarly publications, unique historical collections from the University archives, and teaching tools. The Jefferson Digital Commons allows researchers and interested readers anywhere in the world to learn about and keep up to date with Jefferson scholarship. This article has been accepted for inclusion in Department of Surgery Faculty Papers by an authorized administrator of the Jefferson Digital Commons. For more information, please contact: JeffersonDigitalCommons@jefferson.edu. 


\section{As submitted to:}

Annals of Thoracic Surgery

And later published as:

\section{Extracorporeal membranous oxygenation mimics aortic dissection on CAT}

\section{scan}

Volume 95, Issue 1, January 2013, Page 357

DOI: 10.1016/j.athoracsur.2012.05.125

Philip Batista MD, Nicholas Cavarocchi MD, Hitoshi Hirose MD.

From: Department of Surgery, Thomas Jefferson University, Philadelphia, PA

Key words: ECMO, CAT scan, aortic arch

Running title: CAT scan on ECMO

Corresponding Author:

Hitoshi Hirose, MD, Ph.D.

Department of Surgery, Thomas Jefferson University

1025 Walnut Street Room 605, Philadelphia, PA 19107, USA.

Tel: $\quad 215-955-5654$

Fax: $\quad 215-955-6010$

E-mail: genex@nifty.com

Word count of the main text: 269 . 
A 66 year-old female presented with refractory acute congestive heart failure, cardiogenic shock, and ventricular tachyarrhythmia. Veno-arterial extracorporeal membrane oxygenation (ECMO) was placed via femoral cannulation for salvage and stabilized. CAT scan of the chest performed as a part of heart transplant work-up, demonstrated an unequal distribution of intravenous contrast in the aortic arch (Figure 1). Radiologist's preliminary reading was of "aortic dissection" while in fact this is truly "normal ECMO flow".

During venoarterial ECMO, there is a constant competitive flow between the native cardiac output of the patient and the retrogradely perfusing flow from the arterial femoral cannula of ECMO. As a result, mixing of these two flows will occur at differing points in the aorta dependent on which output is higher. If the ECMO flow is exceeding the native heart function, the mixing will occur in the ascending aorta (Figure 2 left). Conversely, in a state of high cardiac output, mixing transpires in the descending aorta (Figure 2 middle). The CAT scan of this patient clearly demonstrated mixing within the aortic arch (Figure 2 right). In this setting, the intravenous contrast was injected into the right atrium through a central line, whose tip was in close proximity to the venous cannula of the ECMO system. The contrast quickly entered the ECMO circuit and flowed through the femoral arterial cannula up the descending aorta retrograde. Meanwhile, the native heart attempted to eject contrast to the ascending aorta but was unable to due to its poor function and decreased flows compared to ECMO. Upon further discussion with the radiologist, the final diagnosis was normal aorta with altered physiology from femorally inserted ECMO. 
Hirose et al. 3

Figure 1

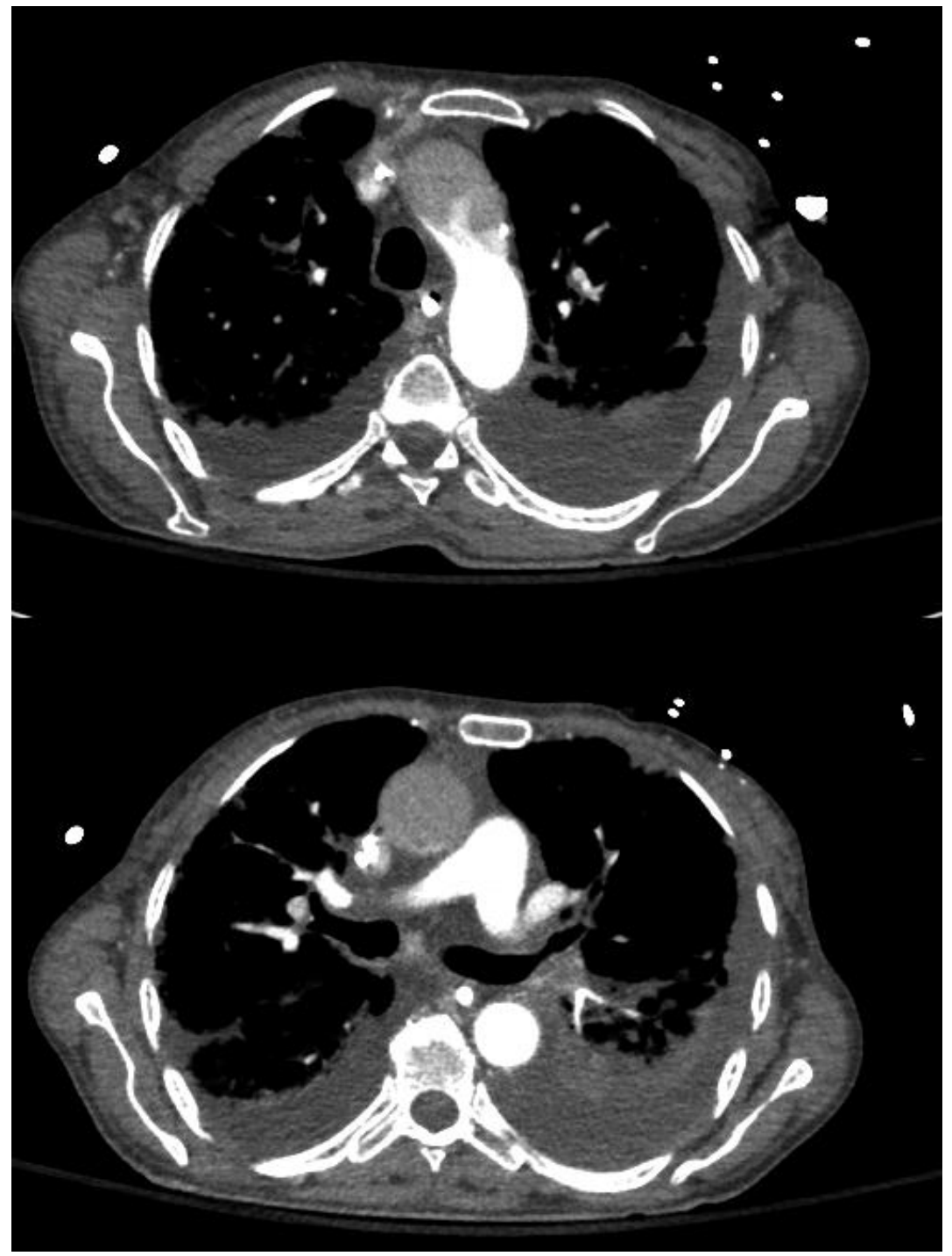


Hirose et al. 4

Figure 2
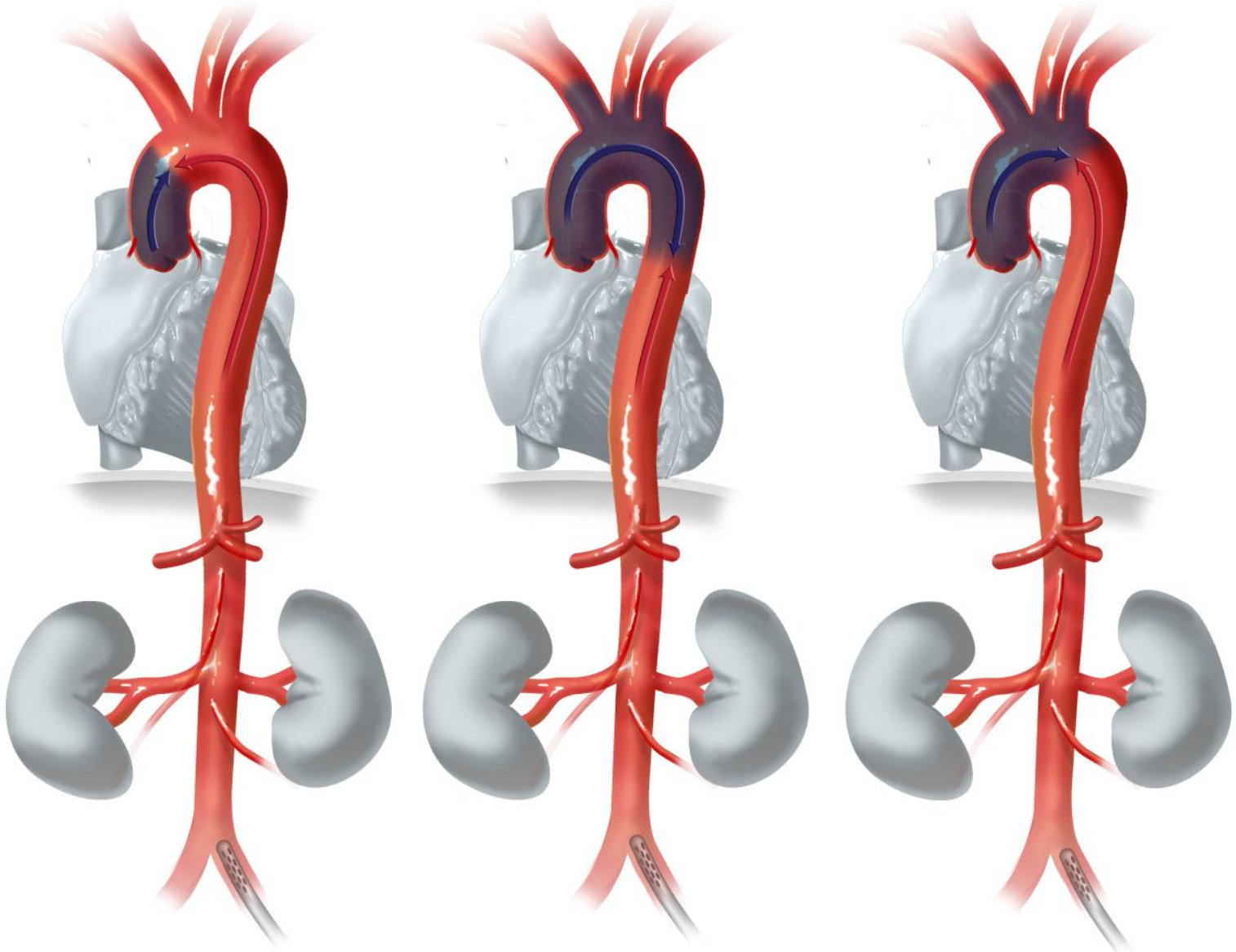